\title{
Relation between Emotional Stability and Time Management Levels among Nurses at one Day Surgeries Hospital
}

\author{
Manal Abdel Monaem Khalifa 1; Safaa Mohamed Abdelrahman 2; Amira Mostafa Fahmy 3 ; Shereen Faiyez Gabra4
}

1. B.Sc. Nursing, Faculty of Nursing-Minia University, Egypt.

2. Professor of Nursing Administration, Faculty of Nursing-Minia University, Egypt.

3. \& 4 Lecturer of Nursing Administration, Faculty of Nursing-Minia University, Egypt

\begin{abstract}
Background: Nurses face many professional challenges. Their jobs are both physically and mentally draining, and on top of working in extremely stressful, pressure-filled environments they have to deal with a seemingly never-ending array of competing priorities and demands on their time, a ton of diverse patient and colleague personalities, and often-grueling work schedules. Aim: assessing relation between emotional stability and time management levels among nurses at one day surgeries hospital. Research design: descriptive research design was utilized in this study. Setting: The study was carried out at the one day surgeries Samalot Hospital. Subject: The subject of the study sample was include all staff nurses who working at the one day surgeries Samalot Hospital during the period of data collection with total numbers 159 nurses Tools: Two tools were used in this study; Emotional Stability questionnaire, and Time management questionnaire. Results: The majority of the sample $(79.9 \%)$ have moderate level of time management, and the majority of the sample (85.5\%) have moderate level of emotional stability,. Conclusions: The majority of the sample had moderate level of emotional stability and time management, there no statistical significance difference between nurses personal data and emotional stability, moreover there no statistical significance difference between nurses personal data and time management. While positive correlation between emotional stability, time management and its dimensions among nurses. Recommendations: Educational workshop and periodical training program should be conducted to all nurses to increase their knowledge and competencies regarding the development of emotional stability and time management
\end{abstract}

Keywords: Emotional Stability \& Time Management

\section{Introduction}

Contemporary organizations around the world increasingly face challenges ranging from downsizing and retrenching, globalization and technological change (Aghion et al., 2014), to financial and geopolitical upheaval in what has been called the new competitive landscape. Such rapid change coupled with new competitors emerging from around the world can stir strong emotions in the workplace, which can have a significant impact on performance even in the largest firms, especially if workplace emotions are not properly managed. This is especially true for firms that have experienced very solid and steady growth for many years, but face increasing disruptive threats from new competitors. Such transformational challenges require that employees manage their emotions well, build trust and adapt to changes quickly rather than treating them like a threat while maintaining good decision making, innovation, and evaluation practices (Li et al., 2014).

In recent years of industrialization, competition, stress and tension, both young and old face difficulties. These difficulties give rise to many psychosomatic problems such as anxiety, tensions, frustrations, and mental upsets. Therefore, the study of Emotional Stability (ES)that deals with the interplay of forces with intensities and quantities is now gaining recognition. Emotional stability is not only one of the effective determinants of the personality patterns, but it also helps to control the growth of person development. The concept of stable emotional behaviour at any level is that which reflects the fruits of the normal emotional development (Joshi, 2016).

Nurses face many professional challenges. Their jobs are both physically and mentally draining, and on top of working in extremely stressful, pressure-filled environments

$P$ a g e | 19 they have to deal with a seemingly never-ending array of competing priorities and demands on their time, a ton of diverse patient and colleague personalities, and often-gruelling work schedules (Mahran et al., 2011).

So emotions and nursing work is an area researched in the health care industry, there are four separate abilities within interpersonal intelligence, such as, the skills in forming groups appropriately, negotiating possible solutions for problems, connecting personally and engaging in social analysis. The interpersonal intelligence is an essential part of nursing work as it needs nurses to understand how patients feel, thereby demonstrate empathy in their care. Further, nursing work involves group work, thus necessitating teamwork, negotiating, and organizing skills for successful performance at health care industry. Managing emotions in organizations enable the organizing function (Mullakanda \&Dissanayake, 2015).

Emotional stability is defined as a property to label the efficiency that an emotional system automatically maintains its equilibrium. Higher emotion stability indicates that an emotion system can recover its equilibrium efficiently (Li et al., 2014). Also according to Ofole, (2017) emotional stability is the process in which the personality is continuously striving for greater sense of emotional health, both intraphysically and intra-personally. It has been emphasized that the emotionally stable individual has the capacity to withstand delay in satisfaction of needs, ability to tolerate a reasonable amount of frustration, belief in long term planning and is capable of delaying or revising his expectations in terms of demands of the situations.

The management of emotions or maintaining emotional stability enables an individual to join or unjoin $\mathrm{him} /$ herself from an emotion in a given situation. It further 
enables the individual to control his/her immediate reactions in the particular situation. When patients are hospitalized for shorter periods of time, there is a need for hospital nurses to be able to form good rapport rapidly with patients. This is necessary for the development of trusting relationships, so that patients feel able to discuss personal, sensitive issues associated with their recovery. Thus, ES of nurses becomes significant factor in health care industry. Thus, care cannot be confined to the physical element but also the psychological and spiritual needs (Mullakanda \& Dissanayake, 2015).

Nurses with greater emotional stability are less likely to exhibit strong emotional reactions to stressful situations, and tend to be more proactive and successful in problemsolving. Effectively managing time is a priority concern in countries where nurses face high pressure (Zapata, 2015). Emotionally stable nurses can thus be expected to achieve better nursing outcomes than emotionally unstable nurses. Emotional stability positively influencing on nursing care quality. Emotionally stable nurses can deal calmly with negative personal emotions without letting them interfere with their rational decision-making, thus protecting patient safety (Mullakanda \&Dissanayake, 2015).

Time is considered the most valuable commodity in our lives, and the development of other sources is dependent on the presence and availability of time. The key to reaching success in life is to concentrate on effective time management (Pehlivan, 2013). Behavior of time management was first defined in late 1950. Time management means to optimally use the time available and that includes aspects of planning, goal setting, prioritizing goals and activities, communications and delegation (Marquis\& Huston, 2012). Individuals can carry out several tasks, perceive their responsibilities and adapt with limitations by managing themselves in a single time through such behavior (Nasri et al., 2013).

Time management is very important in the nursing profession; because the time wasted by nurses, is the time not spent with the patient and it has a negative effect on the quality of care given to patients (Kaya et al., 2012). Recent changes in hospital caregiving have been effective on the work of nurses and the time used by them. It suggests that nurses are required to work more strictly and smartly due to long work hours in order to carry out more of their day to day tasks, in a limited time (Al Khatib, 2014).

\section{Significance of the study:}

Today, nurses job require them to have the ability to have balance between their self -control and emotional stability and managing time at work and care of patient especially in most stressful situations. Through my work in the one day surgeries Samalot Hospital, it was found that most nurses quickly angry, worry and emotionally distressed toward most situations, unable to face their problems, and they didn't arrange their work.

As when they are anger, stressed or depressed, their time management affected negatively. All these issues may affect the care of patients negatively. So the researcher introducing this studies about emotional stability and its relation with time management because it is vital to the nursing and care of patients.

There were no previous studies which linked those two interrelated variables together, but AbdEIhakiem, (2019)studied emotional stability and its relation to decision making at Beni-Suif nursing-Egypt, the study results revealed, a low emotional stability score $(81 \%)$ of the studied subjects and a low decision making scores of $(75.2 \%)$ of the studied subjects.

Aim of the study

- The aim of the current study is to assess relation between emotional stability and time management levels among nurses at one day surgeries hospital

\section{Research questions}

1. What is the level of emotional stability among nurses at the one day surgeries Samalot Hospital?

2. What is the level of time management among nurses at the one day surgeries Samalot Hospital?

3. Are there a relation between emotional stability and time management levels among nurses at the one day surgeries Samalot Hospital?

\section{Subjects and Methods}

Aim of the Study

- The aim of the current study is to assess relation between emotional stability and time management levels among nurses at one day surgeries hospital

\section{Research Design}

Descriptive correlational research design was utilized to fulfill the aim of this study.

\section{Setting:}

The study was conducted the one day surgeries Samalot Hospital located on Arab El Zeina, Madinet Samalot, El Minia ‘Minia Governorate, Egypt.

\section{Subjects}

The subjects of the study sample were included all staff nurses who working at the one day surgeries Samalot Hospital during the period of data collection with total numbers 159 nurses are classified as following:

\begin{tabular}{|l|c|c|c|}
\hline \multicolumn{1}{|c|}{ Department } & $\begin{array}{c}\text { Head } \\
\text { nurse }\end{array}$ & Staff nurse \\
\hline General Surgical (GS) & 2 & 25 & 27 \\
\hline General Medical (GM) & 2 & 15 & 17 \\
\hline $\begin{array}{l}\text { Neonatal Intensive Care Unit } \\
\text { (NICU) }\end{array}$ & 2 & 23 & 25 \\
\hline Dialysis Units & 2 & 28 & 30 \\
\hline Intensive Care Units (ICU) & 3 & 27 & 30 \\
\hline Operating Rooms (OR) & 2 & 28 & 30 \\
\hline \multicolumn{1}{|c|}{ Total } & 13 & 146 & 159 \\
\hline
\end{tabular}

Data collection tools:

Data were collected through the utilization of two tools as follows:

\section{Tool (1): Emotional Stability scale}

It was included two parts:

Part 1: Social demographic data: It used to collect data about nursing staff and encompass item such as age, sex, job, education level, department, years of experience in the nursing field, years of experience in the current department, residence, and attended any workshops related to time management or emotional stability.

\section{Part 2: Emotional Stability questionnaire}

This tool developed by Abo Mostafa (2015) to test emotional stability of nurses. It consists of 27items with five likert scale ranged as ( $5=$ always, $4=$ often, $3=$ sometimes, 
$2=$ rarely, and $1=$ never).The scoring system was ranged from (27 to 135), and it divided into three levels as follow:

- Low emotional stability level from 27 to63.

- Moderate emotional stability level from 64 to 100 .

- High emotional stability level from 101 to 135.

\section{Tool (2): Time management scale}

This part developed by Gazawy(2012) to assess the time management among nurses. It consisted of 53 items; and it was divided into 8 dimensions as follow: fulfillment of obligations( 7 items); district control(6 items); time planning (9 items); setting of priorities ( 7 items); discipline in the use of time(6 items); uses of resources ( 8 items);Negotiation requirements (4 items); and balance of lifestyle (6 items) . Each item was measured by 5 likert scale ranged as: (strongly agree $=5$, agree $=4$, neutral $=3$ disagree $=2$, strongly disagree $=1$ ). The scoring system was ranged from (53 to 265), and it divided into three levels as follow:

- Low time management from 53 to123.

- Moderate time management from 124 to 194.

- High time management from 195 to 265

\section{Validity of Tools:}

The tools were tested for the face validity by a jury of 5 experts in the field of Nursing Administration. The jury composed of one Professor, and one assistant Professor from Faculty of Nursing, Minia University also one Assistant Professors, and two Professors from Faculty of Nursing, Assuit University. Each of the expert panel was asked to examine the instrument for content coverage, clarity, wording, length, format and overall appearance. No necessary modification was done from jury panel.

\section{Reliability of Tools:}

Reliability of the tool was performed to confirm consistency of tool. The internal consistency measured to identify the extent to which the items of the tool measure the same concept and correlate with each other by Cronbach's alpha test. The Cronbach's alpha for the tools categorized as follow:

\begin{tabular}{|l|l|}
\hline tool & $\boldsymbol{\alpha} \boldsymbol{\alpha} \boldsymbol{\alpha}$ \\
\hline 1st tool: Emotional Stability & 0.849 \\
\hline 2nd tool:Time management & 0.888 \\
\hline
\end{tabular}

\section{Pilot Study:}

A pilot study was conducted on $10 \%$ of participants which equal of staff nurses ( 14 nurses +2 head nurse $16=)$ from the one day surgeries Samalot Hospital, to ascertain the clarity, comprehensiveness and applicability of the tools as well as to estimate the appropriate time required to fill the tool. Based on pilot study there was no modification done, and it was added to final results.

\section{Data Collection Procedure:}

- Written approvals were obtained from administrative authorities.

- Meet director of the one day surgeries Samalot Hospital to gain cooperation

- Oral consent from the each participant after explain the aim of this study

- Data was collected using a self-administered tool covering staff nurses data and two tools.

- The tools were distributed to all the staff nurses after explaining the purpose and process of data collection.

- Staff nurses were given from 25 minute to 30 minute to answer them.

- The data collection were collected through three months from beginning of August to end of October 2020

\section{Administrative Design:}

1. A written initial approval was obtained from the research ethics committee of the Faculty of Nursing, Minia University. 2. Permission to conduct the study was obtained from the Dean of the Faculty of Nursing, Minia University .

3. Permission to conduct the study was obtained from director of the one day surgeries Samalot Hospital and head of each department.

\section{Ethical Consideration:}

a) A written consent was obtained from each participant to collect the study data before data collection. After explanation of the purpose of the study, the privacy and confidentiality of the answers were guaranteed by the researcher.

b) Each assessment sheet was coded and participants' names not appeared on the sheets for the purpose of anonymity and confidentiality.

c) The participants were informed that their participation in the study was completely voluntary and there was no harm if they not participate in the study.

\section{Statistical analysis}

- The data obtained from the study tools were categorized, tabulated, analyzed and data entry was performed using the SPSS software (statistical package for social sciences version (25.0).

- Descriptive statistics were applied (e.g. mean, standard deviation, frequency and percentage). Tests of significance were performed to test the study data.

- Pearson's correlation coefficient was applied between quantitative variables. A significant level value was considered when $P<0.05$.

\section{Results}

Table (1) distribution of the personal data regarding to study subjects (no=159).

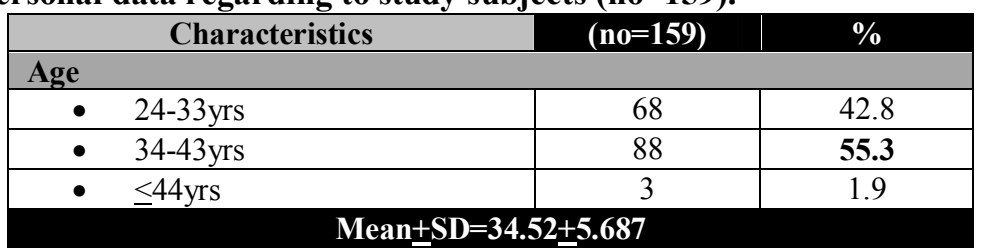


Minia Scientific Nursing Journal (Print - ISSN 2537-012X) (Online - ISSN 2785-9797) Vol. (10) No. (1) December 2021

\begin{tabular}{|c|c|c|}
\hline Characteristics & $(n 0=159)$ & $\%$ \\
\hline \multicolumn{3}{|l|}{ Marital status } \\
\hline - $\quad \underline{\text { Single }}$ & 21 & 13.2 \\
\hline - $\quad$ Married & 135 & 84.9 \\
\hline Divorce & 3 & 1.9 \\
\hline \multicolumn{3}{|l|}{ Qualification } \\
\hline - $\quad$ Diploma degree & 92 & 57.9 \\
\hline - $\quad$ Technical degree & 10 & 6.3 \\
\hline - $\quad$ Bachler's degree & 57 & 35.8 \\
\hline \multicolumn{3}{|l|}{ Years of experience } \\
\hline - $1-10 \mathrm{yrs}$ & 55 & 34.6 \\
\hline - $11-20 y r s$ & 89 & 56.0 \\
\hline - $\quad \leq 21 \mathrm{yrs}$ & 15 & 9.4 \\
\hline \multicolumn{3}{|c|}{ Mean \pm SD $=12.61 \pm 6.308$} \\
\hline \multicolumn{3}{|c|}{ Years of experience in current position } \\
\hline - $1-10 \mathrm{yrs}$ & 62 & 39 \\
\hline - 11-20yrs & 83 & 52.2 \\
\hline - $\quad \leq 21 \mathrm{yrs}$ & 14 & 8.8 \\
\hline
\end{tabular}

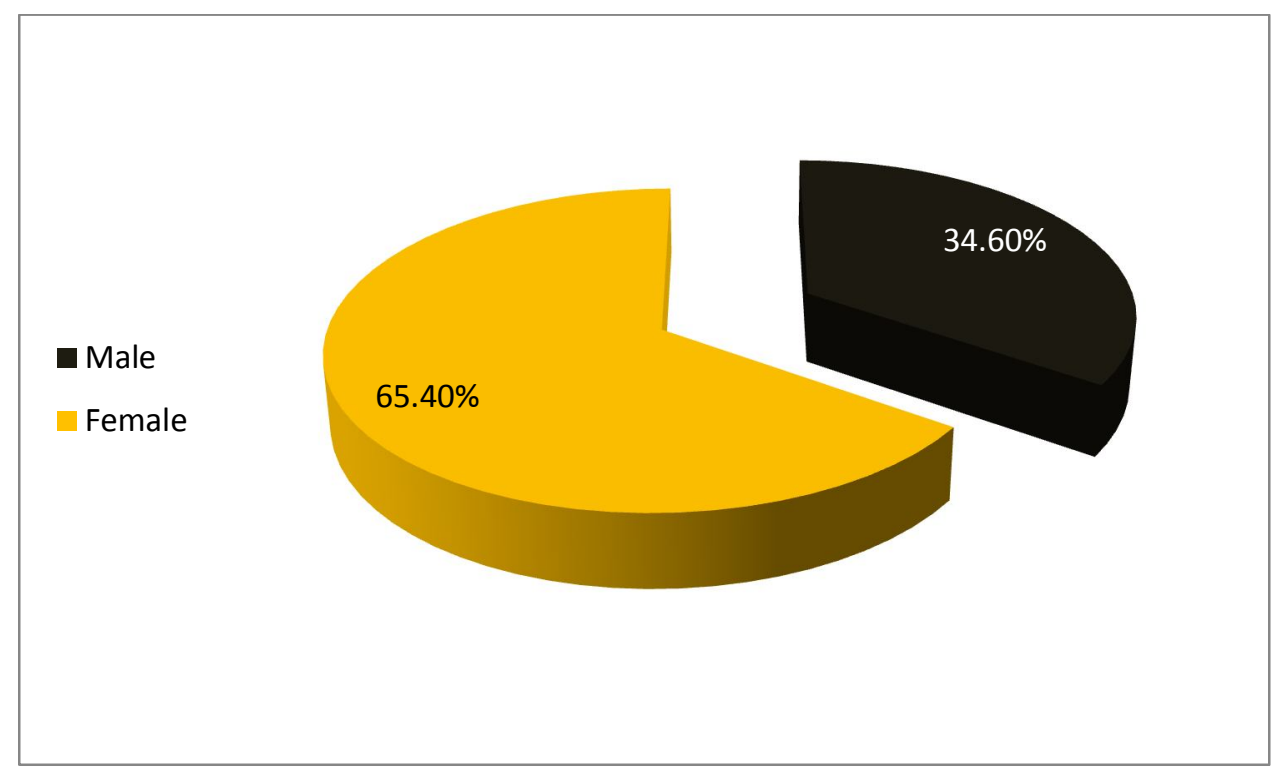

Figure (1) distribution of nurse staff regarding to their sex $(\mathrm{no}=159)$.

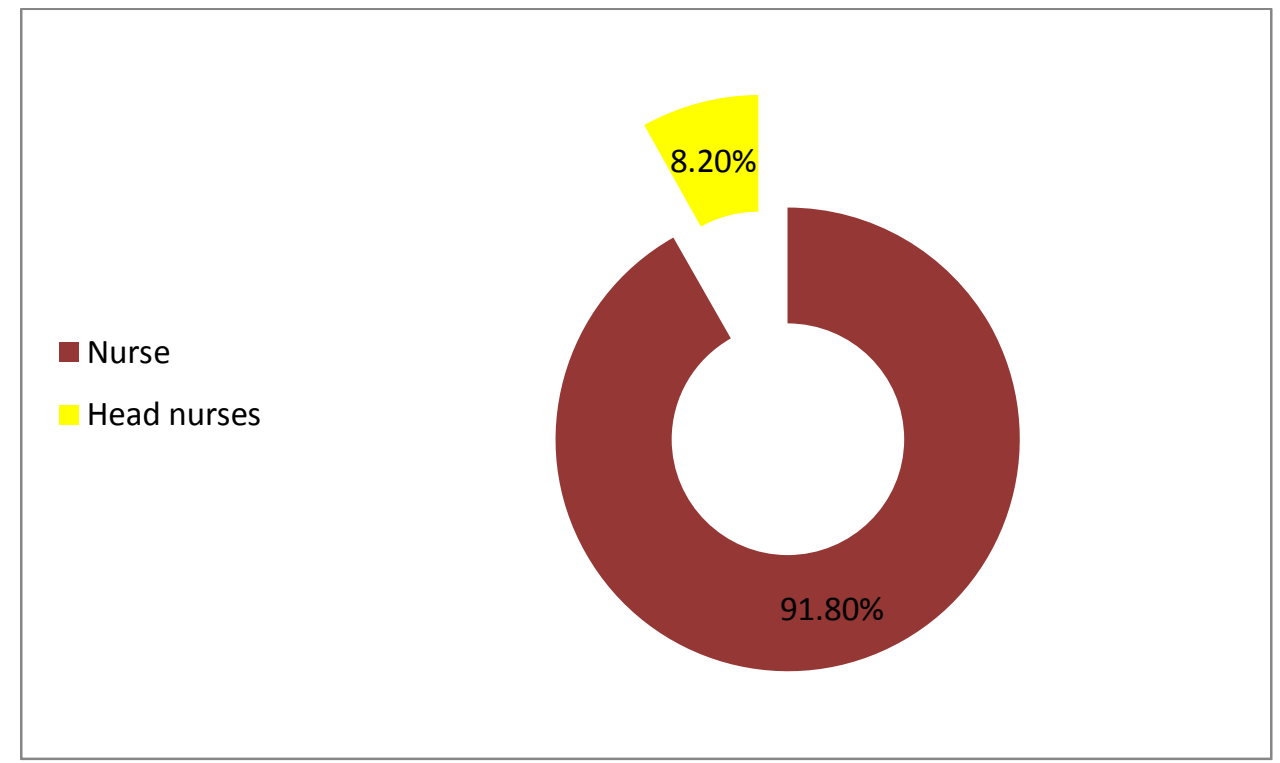

Figure (2) distribution of nurse staff regarding to their job position (no=159). 


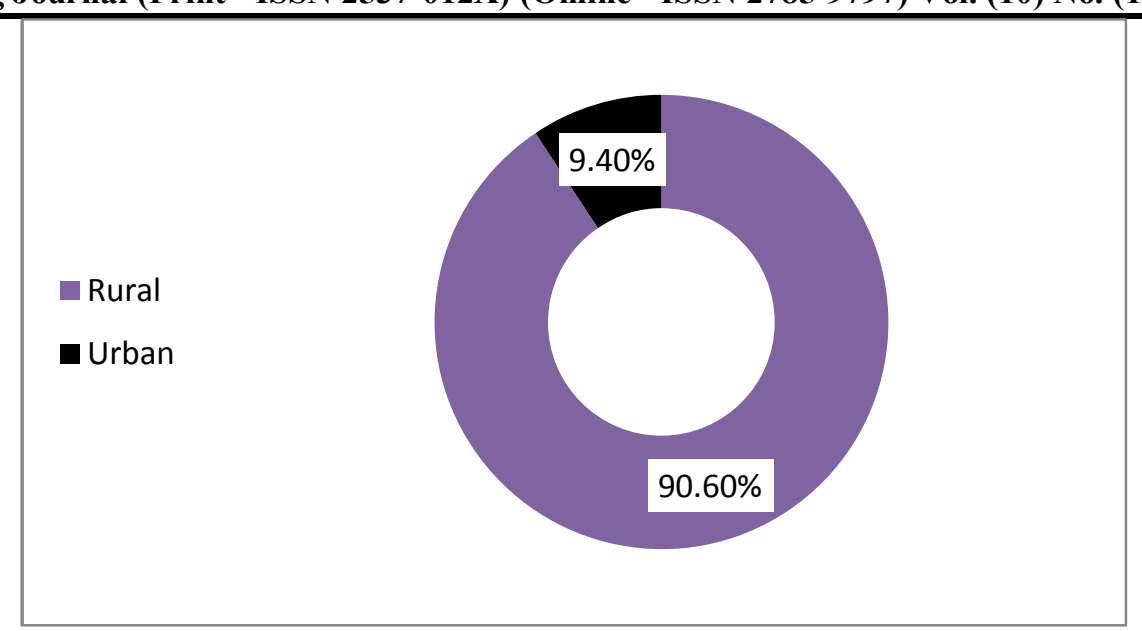

Figure (3) distribution of nurse staff regarding to their residence $(\mathrm{no}=159)$.

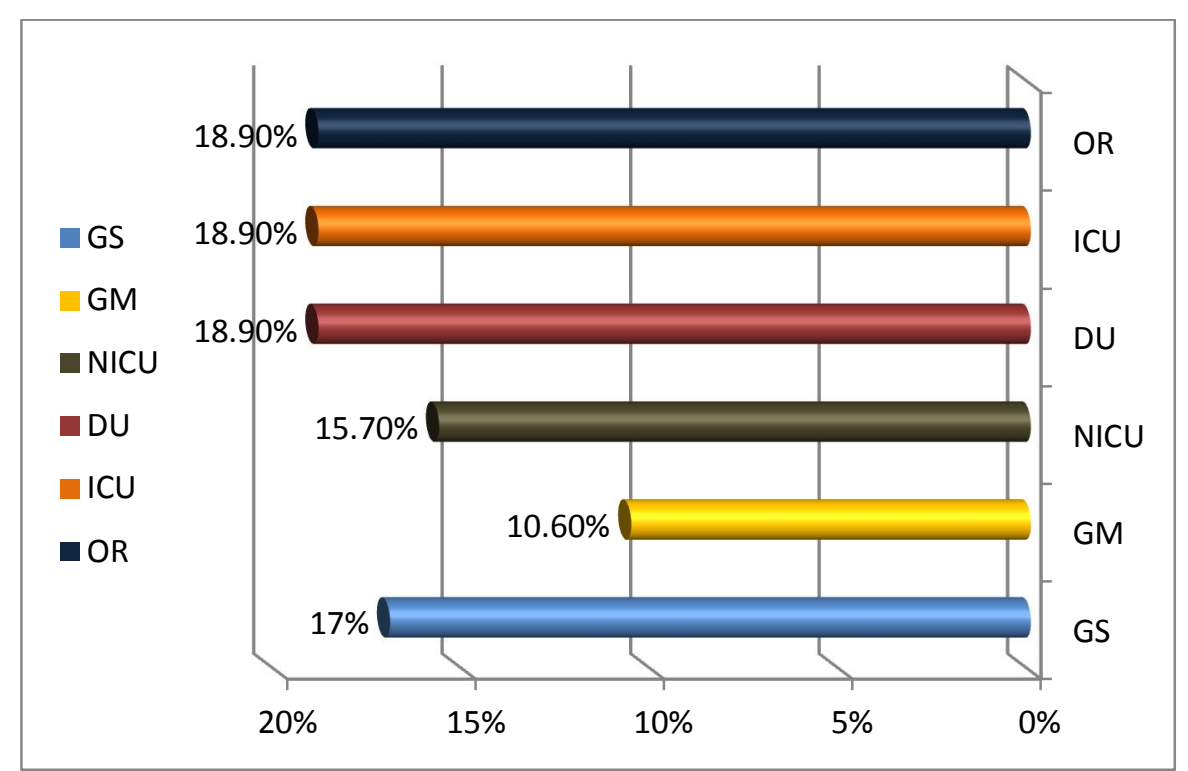

Figure (4) distribution of nurse staff regarding to their departments (no=159).

Table (1) shows that (55.3\%) of nurses age are ranged from 34-43 years old, with mean age 34.52+5.687. Concerning the marital status, it notes that the majority (84.9\%) of them are married. About highest percent (57.9\%) of them are diploma degrees. Regarding nurses years of experience (52.2\%) are 11-20years, with mean $12.19+6.376$.

The figure (1) explains that (65.4\%) of nurses are female. The majority $(91.8 \% \& 90.6 \%)$ of them are nurses and from rural area respectively show in figure (2 \&3). Also figure (4) demonstrates that (18.9\%) of them working on (ICU, DU\& OR).

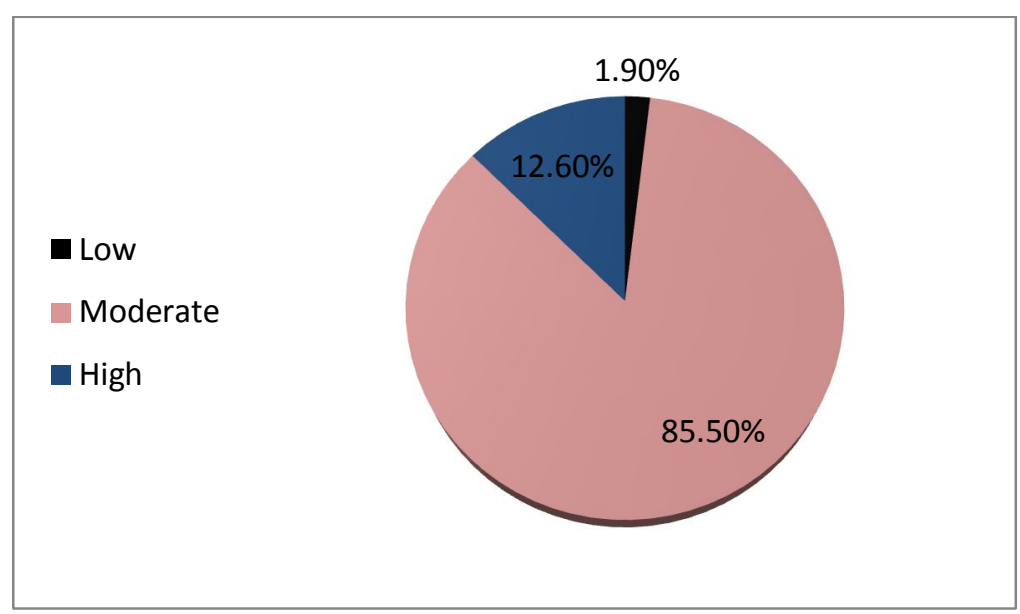

Figure (5) Percentage distribution of staff nurses total emotional stability at the one-day surgeries Samalot Hospital (no=159)

Figure (5) illustrates that the majority of the sample (85.5\%) have moderate level of emotional stability, moreover (12.6\% \& $1.9 \%$ ) of them have high level and low level of emotional stability respectively. 


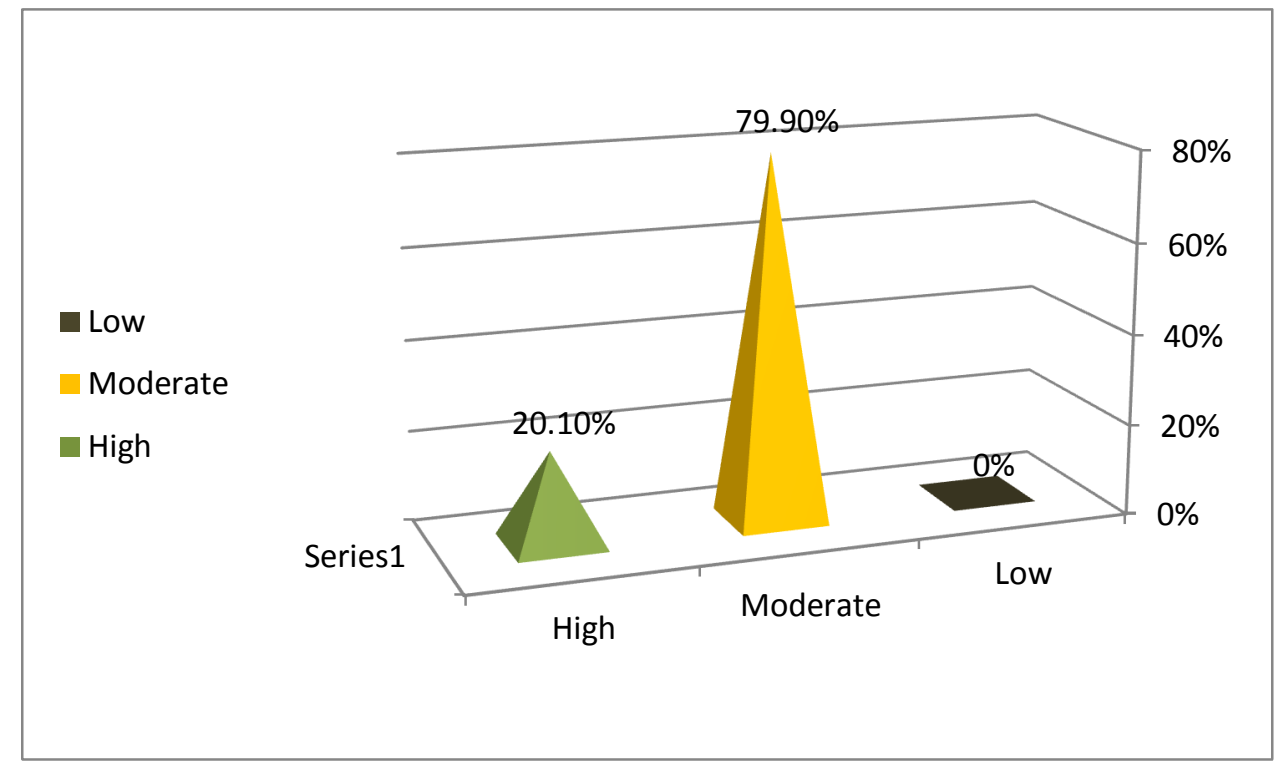

Figure (6) Percentage distribution of staff nurses about total time management at the one-day surgeries Samalot Hospital (no =159)

Figure (6) demonstrates that the majority of the sample (79.9\%) have moderate level of time management, moreover $(20.1 \%)$ of them have high levels of time management.

Table (2) correlation between emotional stability, time management and its dimensions among head nurses and nurses $(\mathrm{N}=$ 159)

\begin{tabular}{|c|c|c|}
\hline Variable & \multicolumn{2}{|c|}{ Emotional stability } \\
\hline & $\mathbf{r}$ & $\mathbf{P}$ \\
\hline Time management & $.203 *$ & .014 \\
\hline Fulfillment of obligations & $.662 * *$ & .000 \\
\hline District control & $.719 * *$ & .000 \\
\hline Time planning & $.839 * *$ & .000 \\
\hline Setting of priorities & $.597 * *$ & .000 \\
\hline Discipline in the use of time & $.540^{* *}$ & .000 \\
\hline Uses of resources & $.752 * *$ & .000 \\
\hline Negotiation requirements & $.268 * *$ & .001 \\
\hline Balance of lifestyle & $.570 * *$ & .000 \\
\hline
\end{tabular}

Table (18) shows that there positive correlation between emotional stability, time management and its dimensions among nurses

\section{Discussion}

Recognition of the emotional impact of patient safety incidents (and medical errors in particular) on both patients and healthcare professionals is growing, the physical, emotional and financial trauma experienced by patients, and the powerful emotional impact of error on healthcare professionals has been described by many authors, health professionals report significant emotional distress in the aftermath of making an error, and in particular, feelings of shame, guilt, fear, panic, shock and humiliation and this distress readily transfers into personal life, creating additional burdens, such as inter-personal conflicts and sleep disturbance, in the workplace feelings of distrust, reduced goodwill and detachment from patients are all described as squeal (Heyhoe et al., 2020).

Time Management is a way to develop and use processes and tools for maximum efficiency, effectiveness, and productivity. It involves mastery of a set of skills like setting goals, planning, and also its effective use of time to achieve desired results, Time management is recognized as an important component of work performance and professional nursing practice, nurses using different strategies of time management. Learning time management skills in nursing lets nurses work smarter instead of harder, this skill is crucial to survive the day to day busy shift, the amount of time required for a nursing member to spend on any activity in nursing practice is important for nursing manager in order to schedule and task allocation (Nayak, 2018).

Concerning the marital status of the study participant, it was noted that the majority of them were married This finding not matched with the study done by Chen et al., 2016 on 1246 nurses in Taiwan to evaluate the influence of work values and personality traits on intent to stay among nurses at various types of hospital in Taiwan and found that about one half of the study participants were married. This may due to setting differences and differences in culture and norms between the two countries.

The results of the current study revealed that more than half of the study participants aged $34-43$ years old and less than two thirds had diploma degree. This finding to some degree not matched with the study done by Manwatkar, \& Mathew, 2016 on 60 participant in India to assess the knowledge of stress management among staff nurses, to evaluate the effectiveness of self-instructional module and to 
compare the level of knowledge on stress management with the selected demographic variables and found that about one half of the study participants were from age group of above 35 years and all the study participants were diploma holders. These findings may due to differences in economic and educational level between the study participants of the two studies.

As regarding years of experience the results of the current study revealed that more than one third of the study participants had 1-10 years of experience with Mean+SD $=12.61+6.308$ (table). This findings not matched with the study done by Shahrour \& Dardas , 2020 on 448 nurses in Gordian to establish the prevalence of acute stress disorders and predictors of psychological distress among Gordian nurses and found that the majority of participant had 10 years ( $\mathrm{SD}=7$ ) of work experience as nurse. These findings may due to difference in inclusion criteria of the selected nurses between the two studies.

According to sex the results of the current study revealed that more than two thirds of the study participants were females (Figure 1). This findings inconsistent with the study done by Dagget, Molla \& Belachew, 2016 on 341 nurses in Ethiopia to assess job related stress and its predictors among nurses working in Jimma Zone public hospitals and found that about one half of the study participants were females. These findings may due to that nursing career in Egypt contain more females than males as it contain only females till recent years.

As regarding to job position the results of the current study revealed that the majority of the study participants were general nurses $(91.8 \%)$. This findings totally consistent with the study done by Wang, et al , 2020 on 1044 registered nurses in China to assess the prevalence of compassion fatigue among Chinese nurses, and to explore the factors associated with compassion satisfaction, burnout and second traumatic stress and also found that that the majority of the study participants were general nurses $(93.9 \%)$. These findings may due to that the number of the staff nurses are higher than the number of the head nurses and that the staff nurses are the direct health care providers who contact with the patients.

As regarding to Percentage distribution of staff nurses total emotional stability the results of the current study revealed that the majority of the study participants had moderate level of emotional stability .This finding contradicted with the study done by Lalonde, \& McGillis Hall , 2017 on 41 preceptors and 44 new graduate nurses in Ontario, Canada to explore the relationships between preceptor characteristics (emotional intelligence, personality and cognitive intelligence) and new graduate nurse socialization outcomes regarding turnover intent, job satisfaction, role conflict and ambiguity during a preceptor ship programmed and found that about three quarters of the study participants had high level of emotional stability. These findings may due to setting differences and cultural differences including (individual's characteristics as level of adaptation and coping to emergent situations) between the study participants.

As regarding to Percentage distribution of staff nurses about total time management the results of the current study revealed that demonstrates that the majority of the study participants had moderate level of time management, moreover less than one quarter of them had high level of time management.This finding to some degree matched with the study done by Dagget, Molla, \& Belachew, 2016 on 341

$P$ a g e | 25 nurses in Ethiopia to assess job related stress and its predictors among nurses working in Jimma Zone public hospitals and found that one third of the study participant had high level of time management and low level of work related stress. These findings may be relay to similarities between the studies nurses in the two studies in socio-demographic characteristics and educational level.

Regarding to correlation between emotional stability, time management and its dimensions among head nurses and nurses the results of the current study revealed that there was a positive correlation between emotional stability, time management and its dimensions among nurses including (Fulfillment of obligations $(\mathrm{P}=0.000)$, Time planning $(\mathrm{P}=$ $0.000)$, Uses of resources $(\mathrm{P}=0.000)$ (Table 18). This finding not matched with the study done by van Mol et al., 2018 on 193 nurses in New York, USA focused on the work engagement of ICU professionals and explored the complex relationship between work engagement, job demands and advantageous personal resources and found that there was no significant correlation between emotional stability and work engagement and fulfillment of demands. These findings might be explained by the work situation, including the demands of multi-tasking, facing sometimes hectic and life-threatening demands, constant alarms, divided attention and requests for help or information that all pose challenges to workflow for nurses.

\section{Conclusion} concluded that:

The majority of the sample had moderate level of emotional stability and time management, there no statistical significance difference between nurses personal data and emotional stability, moreover there no statistical significance difference between nurses personal data and time management. While positive correlation between emotional stability, time management and its dimensions among nurses

\section{Recommendations}

Based on the results of the present study, the researcher came up with the following recommendations:

- Emotional stability and time management skills should be recognized as effective tool that help nurses to improve the nursing skills.

- The selection of nurses at their jobs should be based on emotional stability test.

- Educational workshop and periodical training program should be conducted to all nurses to increase their knowledge and competencies regarding the development of emotional stability and time management

- The managers create an organizational climate that promotes the emotional stability and time management of nurses

\section{Reference}

(1) Abdali Bardeh, M., Naji, S., \& Zarea, K. (2016). The study of job stress and tension management among oncology nurses of Ahvaz Hospitals in 2015. Health Sciences, 5(5), 189-99.

(2) AbdElhakiem, H .F.(2019).Emotional Stability and Its Relation with Decision Making Skills among Nursing EducatorsBeniSuif Nursing Schools

(3) Abo Mostafa, M.S. (2015). The Relationship Between Psychological Stress and Emotional Stability and Decision 
Taking Among Emergency Nurses in Government Hospitals, Master Degree in Community Mental Health. Islamic University of Ghaza.;176-86.

(4) Aghion, P., Akcigit, U., \& Howitt, P. (2014). What do we learn from Schumpeterian growth theory? In Handbook of economic growth (Vol. 2, pp. 515-563). Elsevier.

(5) Al Khatib, A. (2014). Time management and its relation to students' stress, gender and academic achievement among sample of students at $\mathrm{Al}$ Ain University of science and technology. International Journal of Business and Social Research, 4(5), 47-58.

(6) Chen, L. C., Perng, S. J., Chang, F. M., \& Lai, H. L. (2016). Influence of work values and personality traits on intent to stay among nurses at various types of hospital in Taiwan. Journal of Nursing Management, 24(1), 30-38.

(7) Chen, L. C., Perng, S. J., Chang, F. M., \& Lai, H. L. (2016). Influence of work values and personality traits on intent to stay among nurses at various types of hospital in $\mathrm{T}$ aiwan. Journal of Nursing Management, 24(1), 30-38.

(8) Dagget, T., Molla, A., \& Belachew, T. (2016). Job related stress among nurses working in Jimma Zone public hospitals, South West Ethiopia: a cross sectional study. BMC nursing, 15(1), 1-10.

(9) Gazawy, T.A.(2012). Time management and its impact on employees performance at the civil status and passports department in the northern region in jordan from employees perspective. time management and its impact on employees performance at the civil status and passports department in the northern region in jordan from employees perspective.

(10) Heyhoe, J., Birks, Y., Harrison, R., O’Hara, J. K., Cracknell, A., \& Lawton, R. (2020). The role of emotion in patient safety: are we brave enough to scratch beneath the surface? Journal of the Royal Society of Medicine, $109(2), 52-58$.

(11) Joshi, R. (2016). A COMPARATIVE STUDY OF EMOTIONAL STABILITY AND SOCIO-ECONOMIC STATUS OF SECONDARY STUDENTS STUDYING IN GOVERNMEN...

(12) Kaya, H., Kaya, N., Palloş, A. Ö., \& Küçük, L. (2012). Assessing time-management skills in terms of age, gender, and anxiety levels: A study on nursing and midwifery students in Turkey. Nurse education in practice, 12(5), 284288.

(13) Lalonde, M., \& McGillis Hall, L. (2017). Preceptor characteristics and the socialization outcomes of new graduate nurses during a preceptorship programme. Nursing open, 4(1), 24-31.

(14) Li, Y., Ashkanasy, N. M., \& Ahlstrom, D. (2014). The rationality of emotions: A hybrid process model of decision-making under uncertainty. Asia Pacific Journal of Management, 31(1), 293-308.
(15) Mahran, G. S., Taher, A. A., \& Saleh, N. M. (2017). Challenges and work crisis facing critical care nurses. Egyptian Nursing Journal, 14(3), 235.

(16) Manwatkar, S., \& Mathew, S. (2016). A study to assess the effectiveness of self-instructional module among staff nurses regarding stress management in selected hospitals of the city. IOSR Journal of Nursing and Health Science, 5(4), 01-03.

(17) Marquis, B. \& Huston, C. (2012). Leadership roles and management function in nursing. 7 edition, Time Management, 9, by Wolters Kluwer Health China. Lippincott Williams \& Wilkins, pp 182-201.

(18) Mullakanda, P.S., \& Dissanayake, K. (2015). Strategies for maintaining emotional stability: The case of nurses in private health care industry. Management Science Letters, 5, 1097-1110.

(19) Nasri, S., Pazargadi, M., ZagheriTafreshi, M., \&Nassiri, N. (2013). The correlation of head nurses' time management with nurses' job satisfaction in medical \& surgical wards of hospitals in Arak Medical Sciences University. Advances in Nursing \& Midwifery, 23(79), 17.

(20) Nayak, S. G. (2018). Time management in nursing-hour of need. International journal of caring sciences, 11(3), 19972000.

(21) Ofole, N. M. (2017). Impact of emotional maturity on coping with stress among freshmen in South-Western Nigeria universities. Journal of Emerging Trends in Educational Research and Policy Studies, 8(1), 64-73.

(22) Pehlivan, A. (2013). The effect of the time management skills of students taking a financial accounting course on their course grades and grade point averages. International Journal of Business and Social Science, 4(5).

(23) Shahrour, G., \& Dardas, L. A. (2020). Acute stress disorder, coping self $\square$ efficacy and subsequent psychological distress among nurses amid COVID- 19. Journal of nursing management, 28(7), 1686-1695.

(24) van Mol, M. M., Nijkamp, M. D., Bakker, J., Schaufeli, W. B., \& Kompanje, E. J. (2018). Counterbalancing workrelated stress? Work engagement among intensive care professionals. Australian Critical Care, 31(4), 234-241.

(25) Wang, J., Okoli, C. T., He, H., Feng, F., Li, J., Zhuang, L., \& Lin, M. (2020). Factors associated with compassion satisfaction, burnout, and secondary traumatic stress among Chinese nurses in tertiary hospitals: A cross-sectional study. International Journal of Nursing Studies, 102, 103472.

(26) Zapata, A. (2015). The emotional stability and emotional maturity of fourth year teacher education students of the Bulacan state university. Journal of Sciences \& Humanities Research, 1(1), 